\section{A transição da estrutura etária da população brasileira na primeira metade do século XXI}

\author{
The changing age distribution of the Brazilian \\ population in the first half of the 21 st century
}

\author{
${ }^{1}$ Centro de Desenvolvimento \\ e Planejamento Regional, \\ Universidade Federal de \\ Minas Gerais, Belo Horizonte, \\ Brasil. \\ Correspondência \\ J. A. M. Carvalho \\ Centro de Desenvolvimento \\ e Planejamento Regional, \\ Universidade Federal de \\ Minas Gerais. \\ Rua Curitiba 832, 9o andar, \\ Belo Horizonte, $M G$ \\ 30170-120, Brasil. \\ carvalho@cedeplar.ufmg.br
}

\begin{abstract}
Brazil is currently in an advanced stage of both the mortality and fertility transitions, which allows one to confidently forecast the age distribution and population size over the next four decades. Whereas the elderly population $(\geq 65$ years) will increase at high rates (2-4\% per year), the young population will decline. According to United Nations projections, the elderly population will increase from $3.1 \%$ of the population in 1970 to $19 \%$ in 2050. Meanwhile, within the young and adult populations, growth rates will vary among different age groups, ranging from negative to positive values. The changing age distribution of the Brazilian population brings opportunities and challenges that could lead to serious social and economic issues if not dealt with properly in the coming decades.
\end{abstract}

Demographic Transition; Age Distribution; Demographic Aging
José Alberto Magno de Carvalho 1

Laura L. Rodríguez-Wong 1

\section{Introdução}

Este artigo analisa a provável trajetória da estrutura etária da população brasileira durante a primeira metade do século XXI, dando ênfase especial ao rápido envelhecimento populacional. Há de se chamar atenção para dois pontos essenciais:

- Por se tratar de projeções, os mais céticos podem se sentir inclinados a tomá-las como um simples exercício de futurologia, em que inúmeros cenários alternativos seriam prováveis. Sucede que a transição da mortalidade e a transição da fecundidade, forças motoras da transição demográfica brasileira, já avançaram muito, sendo muito improvável a reversão de suas tendências, diante das evidências históricas naqueles países que vivenciaram sua transição demográfica em épocas anteriores, especialmente aqueles da Europa Ocidental, entre o final do século XIX e segunda metade do século XX.

As grandes mudanças que se darão doravante, quais sejam, profunda modificação da estrutura etária e rápido declínio do ritmo de crescimento populacional, serão conseqüência das transições, basicamente já definidas, da mortalidade e da fecundidade do país. Conseqüentemente, a trajetória a ser apresentada neste trabalho tem, em suas linhas gerais, pequena probabilidade de erro, ainda que se trabalhe com uma população fechada, isto é, sem fluxos migratórios internacionais. Para que fluxos 
internacionais interfiram significativamente na trajetória exposta (ritmo de crescimento e distribuição etária), terão que ser em volumes tão grandes e com tal especificidade etária que se tornam altamente improváveis.

- Em um país caracterizado pelo imediatismo, onde a sociedade não tem tradição de pensar e, conseqüentemente, assumir posições políticas que tenham como objetivos resultados no médio e longo prazos, a muitos pode parecer um simples exercício acadêmico, sem praticidade alguma, visualizar e analisar a evolução do tamanho e da estrutura da população brasileira nas próximas quatro ou cinco décadas. No entanto, há que se definir e implantar políticas públicas, de modo a tirar proveito das oportunidades criadas e a enfrentar os desafios a serem gerados pelo novo padrão demográfico.

As oportunidades aparecerão, sobretudo, em curto e médio prazos. Se não forem aproveitadas no tempo devido, serão definitivamente perdidas. Os desafios se tornarão patentes daqui a duas ou três décadas, mormente os que se referem ao envelhecimento populacional. Para que não se transformem em problemas praticamente insolúveis, medidas têm de ser tomadas, já no curto e médio prazos, tais como aquelas relacionadas aos investimentos em crianças e jovens e as reformas institucionais nas áreas de saúde e da previdência, particularmente nesta última, cujos resultados permanentes só se farão sentir no longo prazo.

O tema deve interessar a todos, não apenas como cidadãos preocupados com o bem-estar coletivo das gerações futuras, mas também do ponto de vista do interesse individual. Basta atentar para o fato de que, de todas as pessoas residentes no Brasil em 2005, em torno de $87 \%$ estarão vivas em 2025 (população, então, com vinte ou mais anos), e de 61\%, em 2050 (população, então, com cinqüenta anos ou mais de idade).

\section{Material e métodos}

Este estudo se vale das estimativas de população da Divisão de População da Organização das Nações Unidas ${ }^{1}$ e do Instituto Brasileiro de Geografia e Estatística (IBGE) 2. Trata-se, em ambos os casos, de projeções de população obtidas por intermédio do "método das componentes", assim denominado porque considera a variação do tamanho da população e de sua distribuição por idade como função do comportamento provável, no futuro, dos três componentes demográficos: fecundidade, mortalidade e migração ${ }^{3,4}$. Esse método, eminentemente demográfico, garante, em geral, uma margem de segurança bastante maior que modelagens de tipo matemático ou probabilístico.

\section{A transição da estrutura etária}

Entre os anos 40 e 60, o Brasil experimentou um declínio significativo da mortalidade, mantendose a fecundidade em níveis bastante altos, produzindo, assim, uma população quase-estável jovem e com rápido crescimento 5 . A partir do final da década de 60 , a redução da fecundidade, que se iniciou nos grupos populacionais mais privilegiados e nas regiões mais desenvolvidas, generalizou-se rapidamente e desencadeou o processo de transição da estrutura etária, que levará, provavelmente, a uma nova população quase-estável, mas, desta vez, com um perfil envelhecido e ritmo de crescimento baixíssimo, talvez negativo.

Essa transformação, que ocorre também em intensidades diferentes, na maioria dos países em desenvolvimento, particularmente da América Latina (Figura 1), implica a diminuição, em termos relativos (e, às vezes, transitoriamente, em termos absolutos), da população jovem. No caso do Brasil, a presença de crianças com menos de cinco anos reduziu-se, entre 1970 e 1990, de $15 \%$ para $11 \%$.

A participação do grupo etário de 5 a 9 anos declinou de $14 \%$ para $12 \%$. A proporção de crianças nestes dois grupos de idade continuou decrescendo, chegando, em 2000, a tamanhos similares (cada um representava cerca de $9 \%$ da população total). Complementarmente, os grupos mais velhos aumentaram sua participação; a população de 65 anos ou mais, por exemplo, aumentou de 3,1\%, em 1970, para 5,5\%, em 2000. O formato, até então extremamente piramidal, da estrutura etária começou, então, de sua base, a desaparecer, anunciando um rápido processo de envelhecimento e uma distribuição praticamente retangular, no futuro.

\section{As relações intergeracionais}

As transformações na estrutura por idade alteram, obviamente, as relações intergeracionais. Isso pode ser visto, em primeiro lugar, pela evolução da participação dos três grandes grupos etários (menos de 15 anos, de 15 a 64 anos e 65 anos e mais) na população total (Figura 2), no período 1950-2050. A composição da população permaneceu, como dito, quase-estável, até o início dos anos 70. A partir de então, inicia-se o rápido processo de desestabilização da estrutura etária brasileira. As mudanças mais acentuadas 
Figura 1

Distribuição etária relativa. Brasil e América Latina e Caribe, 1975-2050.

1a) 1975

América Latina e Caribe

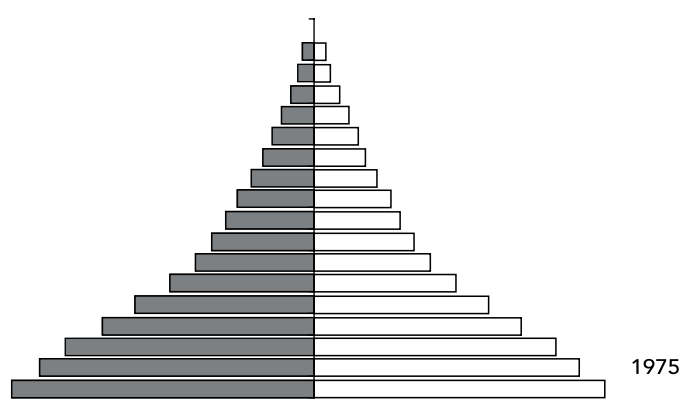

1b) 2000

América Latina e Caribe

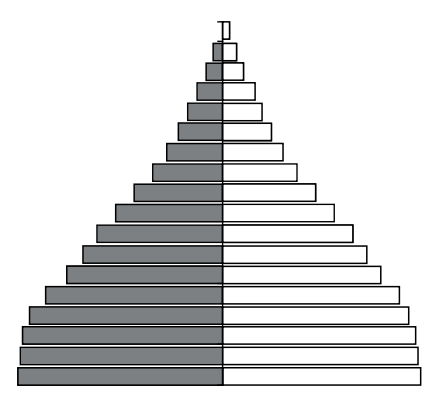

1c) 2025

América Latina e Caribe

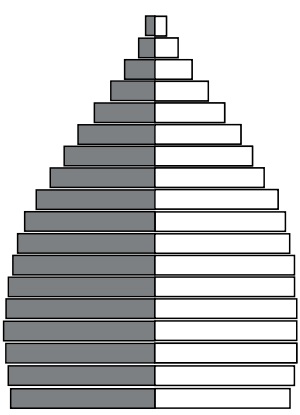

1d) 2050

América Latina e Caribe

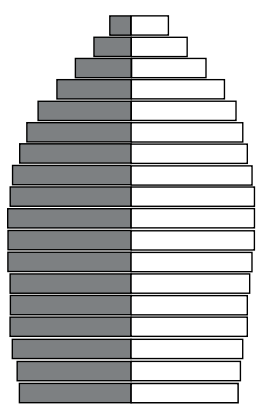

Brasil

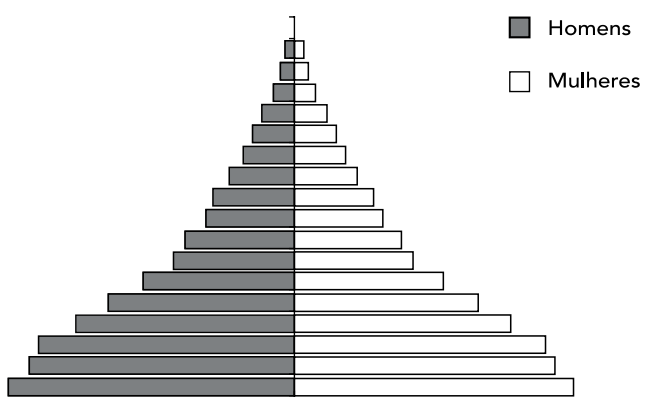

Brasil

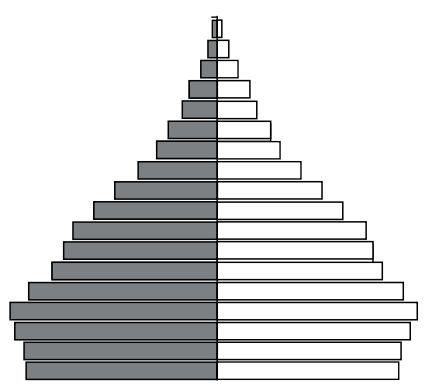

Brasil

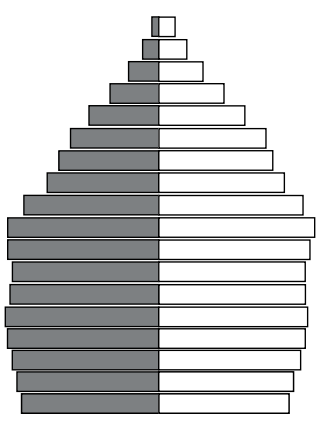

Brasil

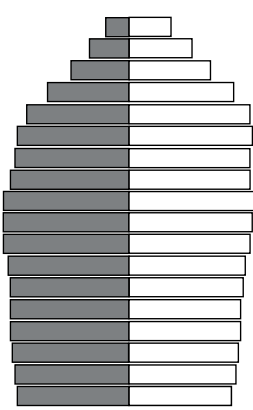

Fonte: Organização das Nações Unidas 1. 


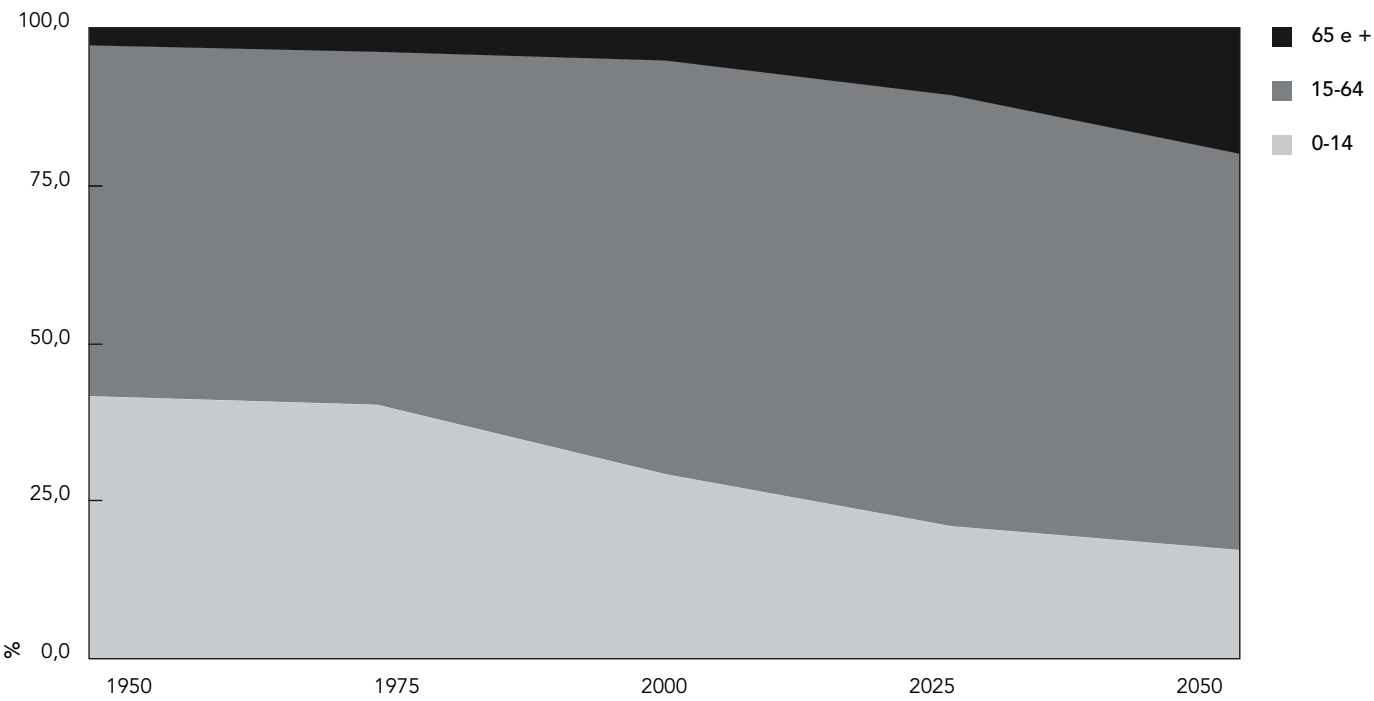

Fonte: Organização das Nações Unidas 1 (dados básicos).

se operam nas idades extremas: os menores de 15 anos perderam representatividade, desde os anos 70; os maiores de 65 anos apresentarão peso relativo crescente durante toda a primeira metade deste século.

A alteração nas relações intergeracionais pode ser vista, também, pela Razão de Dependência (RD) e do Quociente Idosos-Jovens (QIJ) (Tabela 1).

A Razão de Dependência Total (RDT) não retornará aos altos níveis registrados durante os três primeiros quartos do século passado (em torno de $80 \%$ ), devendo estabilizar-se ao redor de 58\%, embora a Razão de Dependência dos Idosos (RDI) provavelmente duplicar-se-á, entre 2000 e 2025, e quadruplicar-se-á, se considerado o período 2000-2050.

O enorme crescimento da RDI será mais do que compensado, na constituição da RDT, pelo grande declínio da Razão de Dependência de Jovens (RDJ), que deverá se estabilizar ao redor de $28 \%$, a partir de 2050 . Há de se atentar para o fato de que a abrupta queda da RDT, durante a segunda metade do século passado, de $80 \%$ para aproximadamente $55 \%$, deu-se pelo declínio da RDJ. Por outro lado, durante o período 2000-2050, haverá relativa estabilidade na RDT, no entanto com profunda mudança em sua composição: enquanto em torno de $85 \%$ da RDT, em 2000 , era devida à população jovem, sua contribuição, em 2050, será, provavelmente, menor do que $50 \%$.

O QIJ, referido com freqüência como Índice de Envelhecimento, é uma medida que considera apenas os dois grupos etários extremos, aqueles mais afetados pelas atuais mudanças demográficas. Sua evolução mostra a velocidade do processo de envelhecimento. Comparações feitas por Moreira 6 apontam o Brasil entre os países com o ritmo mais acentuado de crescimento deste QIJ nas próximas décadas. Em 2025, o QIJ será, provavelmente, quase cinco vezes maior do que aquele observado em 1975. Para cada conjunto de 100 jovens menores de 15 anos, deverá haver em torno de 46 idosos, em 2025, contra 10, em 1975. Em 2050, o número de pessoas idosas ultrapassaria o de crianças (Tabela 1).

\section{Oscilações e ritmos diferenciados de crescimento populacional}

Pode-se alcançar uma melhor compreensão da trajetória da transição da estrutura etária brasileira no período de 2000 a 2050, ao se considerarem taxas médias de crescimento anual de grupos etários mais específicos (Tabela 2). As populações nos grupos de 0-14 e 15-24 anos, nascidas depois de 1975, portanto durante o período 
Razões de Dependência (RD) e Quociente Idosos-Jovens (QIJ). Brasil, 2000-2050.

\begin{tabular}{|c|c|c|c|c|c|c|c|}
\hline \multirow[t]{3}{*}{ Período } & \multicolumn{6}{|c|}{ RD } & \multirow[t]{3}{*}{ QlJ (x 100) \# } \\
\hline & \multicolumn{3}{|c|}{ Razão (x 100) } & \multicolumn{3}{|c|}{ Distribuição relativa (\%) } & \\
\hline & Total * & Jovem ** & Idosa $\star \star \star ~$ & Total & Jovem & Idosa & \\
\hline 1950 & 80,3 & 74,9 & 5,4 & 100,0 & 93,3 & 6,7 & 7,2 \\
\hline 1975 & 79,2 & 72,2 & 7,0 & 100,0 & 91,2 & 8,8 & 9,6 \\
\hline 2000 & 54,3 & 45,9 & 8,4 & 100,0 & 84,6 & 15,4 & 18,3 \\
\hline 2025 & 48,7 & 33,4 & 15,3 & 100,0 & 68,6 & 31,4 & 45,7 \\
\hline 2050 & 57,8 & 28,1 & 29,7 & 100,0 & 48,6 & 51,4 & 105,6 \\
\hline
\end{tabular}

Fonte: Organização das Nações Unidas 1 (até 1975, dados brutos); Instituto Brasileiro de Geografia e Estatística 2 (2000 em diante).

* Razão de Dependência Total (RDT) = Razão de Dependência de Jovens (RDJ) + Razão de Dependência de Idosos (RDI);

** RDJ = população menor de 15 anos/população de 15-64;

*** RDI = população de 65 anos ou mais/população de 15-64;

\# QIJ = população com 65 anos ou mais/população com menos de 15 anos.

de declínio da fecundidade, aumentarão, nos primeiros anos do presente século, a taxas bem abaixo do valor médio da população total. A partir de 2020 (grupo de 0-14anos) e de 2030 (grupo de 15 a 24 anos) deverão apresentar, inclusive, taxas negativas de crescimento.

A população de 25 a 64 anos, em que se concentra a força de trabalho, apresentou até 2005 taxas de crescimento acima de $2 \%$. Seu ritmo de aumento sofrerá forte desaceleração, já no curto prazo, e seu tamanho absoluto deverá se estabilizar por volta de meados do século XX. Os grupos acima de 65 anos aumentarão a taxas positivas e altas durante todo o período. Taxas de crescimento superiores a $4 \%$ são esperadas para a população de 75 anos e mais, durante grande parte da primeira metade do presente século.

É este padrão de crescimento diferenciado por idade, baixo ou negativo, no segmento jovem; médio ou baixo, para a população em idade ativa, até 2025, e praticamente nulo no restante do período; muito alto no contingente de idosos, que caracterizará a transição da estrutura etária brasileira durante a primeira metade do presente século.

As conseqüências de diferentes taxas de crescimento, no tamanho absoluto da população dos vários grupos etários, torna-se uma questão importante a ser considerada. Apesar de a fecundidade já ter alcançado o nível de reposição e de, certamente, atingir níveis ainda mais baixos, no futuro próximo, a população como um todo deverá ainda crescer durante o período analisado, ainda que a um ritmo rapidamente decrescente. Conviverão grupos etários que diminuirão, em termos absolutos, com outros crescendo rapidamente (população idosa) (Figura 3).

As projeções mais recentes prevêem que, entre 2000 e 2050, 88 milhões de pessoas serão, provavelmente, adicionadas à população total 1 . Apesar disso, entre os jovens, como já visto, taxas de crescimento negativas prevalecerão, o que trará, como conseqüência, a diminuição no número absoluto deste segmento populacional. Durante o período, o tamanho da população com menos de 15 anos deverá decrescer em algo próximo de cinco milhões. Enquanto, entre 2000 e 2050, a população total deverá crescer cerca de $50 \%$, aquela abaixo de 15 anos declinaria em torno de $10 \%$. No último qüinqüênio analisado, 2045-2050, a população total do país cresceria, por ano, a uma taxa média de apenas $0,28 \%$ (muito próxima de crescimento nulo), aquela abaixo de 15 anos diminuiria a um ritmo de $0,46 \%$ ao ano. A população idosa ainda aumentaria, anualmente a $2,4 \%$ (Tabela 2).

O aumento populacional se dará entre adultos e, principalmente, idosos. Entre os adultos, todavia, haverá, já a partir de 2005, subgrupos etários crescendo a taxas negativas (Tabela 3). O volume anual de população que se incorporará à faixa etária de 65 anos e mais aumentará continuamente. Em média, anualmente, o acréscimo será, talvez, de mais de 550 mil idosos, no primeiro quartel do século XXI, e superará a casa de um milhão, entre 2025 e 2050.

A Tabela 3 apresenta a variação do tamanho absoluto da população dos diversos grupos qüinqüenais de idade, nos qüinqüênios compreendidos ente 2000 e 2050. Os números da tabela 
Taxa média anual de crescimento (\%) da população, por grupos etários. Brasil, 2000-2050.

\begin{tabular}{|c|c|c|c|c|c|c|}
\hline \multirow[t]{2}{*}{ Período } & \multirow[t]{2}{*}{ Total } & \multicolumn{5}{|c|}{ Grupo etário (anos) } \\
\hline & & $0-14$ & $15-24$ & $25-64$ & $65-74$ & 75 e + \\
\hline $2000-2005$ & 1,45 & 0,17 & 0,77 & 2,26 & 3,05 & 4,97 \\
\hline 2010-2015 & 1,15 & 0,20 & $-0,25$ & 1,77 & 3,18 & 4,05 \\
\hline $2020-2025$ & 0,87 & $-0,48$ & 0,64 & 0,95 & 4,30 & 3,91 \\
\hline 2030-2035 & 0,63 & $-0,33$ & $-0,59$ & 0,70 & 2,34 & 4,54 \\
\hline $2045-2050$ & 0,28 & $-0,46$ & $-0,36$ & $-0,05$ & 2,48 & 2,38 \\
\hline
\end{tabular}

Fonte: Instituto Brasileiro de Geografia e Estatística 2 (dados brutos).

Figura 3

População acumulada até a idade indicada (anos). Brasil, 2000-2050.

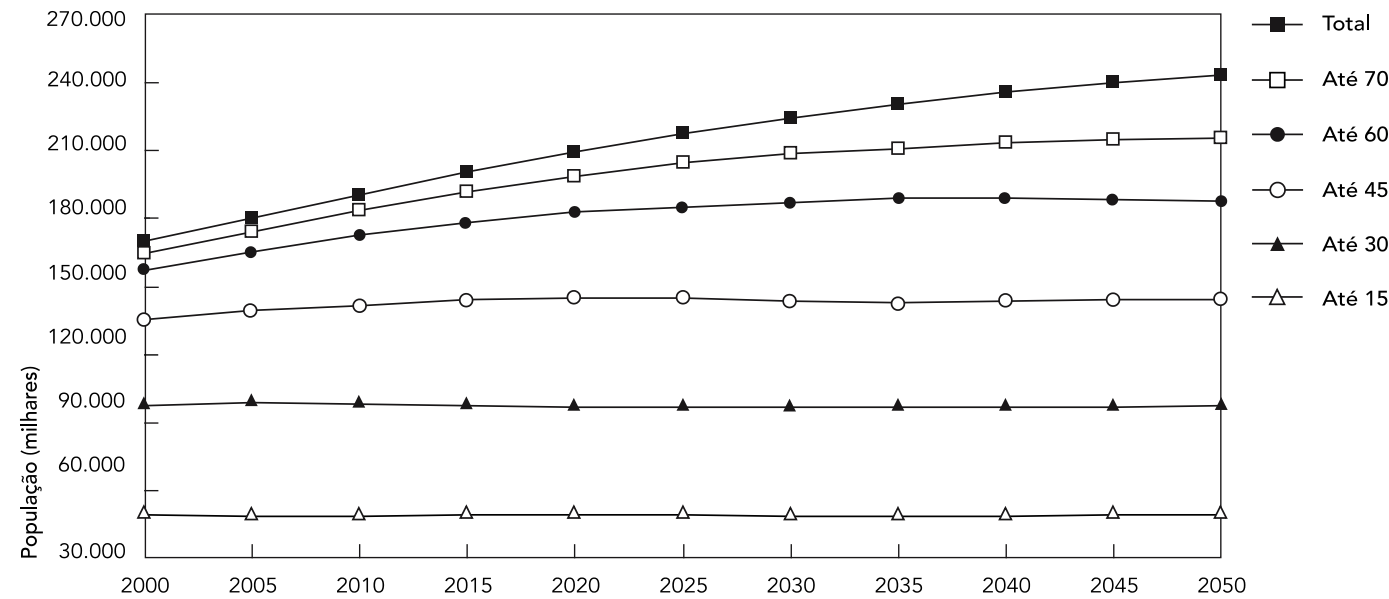

Fonte: Instituto Brasileiro de Geografia e Estatística 2 (dados brutos).

ilustram como o crescimento negativo, advindo de declínio no número de nascimentos, se espalha pela pirâmide etária, à medida que se avança no tempo.

Entre 2000 e 2005, houve diminuição do tamanho absoluto da população nos grupos etários de 10 a 14 e naquele de 15 a 19 anos. Isso se explica pelo fato de que no número de nascimentos decresceram, entre os qüinqüênios 1980-1985, 1985-1990 e 1990-1995. Logo, haverá sempre declínio do número de indivíduos, com o passar do tempo, naqueles grupos etários em que, entre aquelas três gerações, a mais velha for substituída pela mais jovem. Trata-se de fenômeno registrado pela primeira vez no País e que terá impacto sobre o número absoluto de idosos (65 anos e mais) apenas a partir de 2050. Contudo, mesmo então, a população idosa continuará a crescer, mesmo que em ritmo menor, e não haverá declínio na proporção da população brasileira por ela constituída, pois estará ocorrendo, concomitantemente, diminuição de pessoas em todas as idades abaixo de 45 anos (Tabela 3). Isso porque se prevê que o número de nascimentos no país cairá durante todo o período compreendido entre 2010 e 2050. 
Variação absoluta da população (em milhares), em períodos qüinqüenais, segundo grupo etário. Brasil, $2000-2050$.

\begin{tabular}{|c|c|c|c|c|c|c|c|c|c|c|}
\hline $\begin{array}{l}\text { Grupo etário } \\
\text { (anos) }\end{array}$ & $2000-2005$ & $2005-2010$ & 2010-2015 & $2015-2020$ & $2020-2025$ & $2025-2030$ & $2030-2035$ & $2035-2040$ & $2040-2045$ & 2045-2050 \\
\hline Total & 12.904 & 12.650 & 11.634 & 10.610 & 9.796 & 8.864 & 7.585 & 6.095 & 4.780 & 3.572 \\
\hline $0-4$ & 893 & 190 & -567 & -507 & -206 & -210 & -413 & -516 & -295 & -268 \\
\hline $5-9$ & 496 & 905 & 205 & -554 & -498 & -199 & -204 & -409 & -512 & -292 \\
\hline $10-14$ & -965 & 500 & 908 & 208 & -551 & -495 & -197 & -203 & -407 & -511 \\
\hline $15-19$ & -564 & -952 & 507 & 912 & 214 & -544 & -489 & -193 & -199 & -405 \\
\hline $20-24$ & 1.885 & -544 & -930 & 517 & 920 & 223 & -534 & -481 & -187 & -194 \\
\hline $25-29$ & 1.421 & 1.890 & -518 & -906 & 529 & 928 & 233 & -523 & -472 & -181 \\
\hline $30-34$ & 467 & 1.431 & 1.897 & -491 & -882 & 540 & 936 & 243 & -512 & -463 \\
\hline $35-39$ & 613 & 487 & 1.441 & 1.903 & -465 & -857 & 551 & 943 & 252 & -501 \\
\hline $40-44$ & 1.866 & 630 & 508 & 1.449 & 1.906 & -438 & -831 & 562 & 950 & 262 \\
\hline $45-49$ & 1.830 & 1.852 & 648 & 529 & 1.454 & 1.904 & -408 & -800 & 573 & 955 \\
\hline $50-54$ & 1.506 & 1.800 & 1.831 & 663 & 548 & 1.452 & 1.893 & -375 & -763 & 584 \\
\hline $55-59$ & 1.086 & 1.466 & 1.757 & 1.795 & 674 & 564 & 1.442 & 1.870 & -336 & -718 \\
\hline $60-64$ & 454 & 1.044 & 1.412 & 1.697 & 1.742 & 680 & 577 & 1.419 & 1.830 & -292 \\
\hline 65-69 & 715 & 443 & 987 & 1.336 & 1.609 & 1.661 & 676 & 582 & 1.376 & 1.762 \\
\hline $70-74$ & 285 & 645 & 421 & 904 & 1.225 & 1.479 & 1.535 & 651 & 571 & 1.297 \\
\hline $75-79$ & 459 & 254 & 551 & 379 & 784 & 1.064 & 1.290 & 1.345 & 593 & 531 \\
\hline $80 e+$ & 458 & 608 & 576 & 776 & 794 & 1.112 & 1.530 & 1.978 & 2.321 & 2.007 \\
\hline $65 e+$ & 1.917 & 1.951 & 2.536 & 3.395 & 4.412 & 5.317 & 5.030 & 4.557 & 4.860 & 5.597 \\
\hline
\end{tabular}

Fonte: Instituto Brasileiro de Geografia e Estatística 2

\section{A população idosa}

Como já visto, o maior ritmo de crescimento da população idosa é que levará ao envelhecimento populacional. De $3,1 \%$, em 1970, as pessoas com 65 ou mais anos de idade deverão corresponder, em 2050, a aproximadamente $19 \%$ da população brasileira. A população idosa, por sua vez, sofrerá uma profunda mudança em termos de sua distribuição interna, tanto etária, quanto entre os sexos.

A Tabela 4 apresenta os números referentes à população de 65 ou mais anos de idade observados, em 2000, e projetados, em 2025 e 2050, relativos a homens e mulheres, assim como as razões de sexo.

Enquanto $17 \%$ dos idosos, de ambos os sexos, em 2000, tinham 80 anos ou mais de idade, em 2050 corresponderão, provavelmente, a aproximadamente $28 \%$. Entre as mulheres, o peso das mais idosas passará de $18 \%$ para em torno de $30,8 \%$. Isso significará um grande envelhecimento da própria população idosa.

Para cada grupo de 100 mulheres idosas, havia, em 2000, ao redor de 81 homens idosos; em 2050, haverá, provavelmente, apenas em torno de 76 idosos do sexo masculino. Entre aqueles com 80 ou mais anos de idade, para cada conjunto de 100 mulheres, o número de homens deverá cair, entre 2000 e 2050, de 71 para 61. Haveria, pois, em meados do século, quase duas mulheres para cada homem, entre aqueles mais idosos!

Deve-se observar na Tabela 4 que, entre os anos 2025 e 2050, haveria um aumento da razão de sexo nos grupos qüinqüenais ente $65 \mathrm{e}$ 79 anos. Isso se daria porque se prevê, nas projeções, que as coortes nascidas após 1980 experimentariam, concomitantemente ao declínio da mortalidade, uma diminuição da sobremortalidade masculina. Esta se daria especialmente após os 40 anos de idade. Trata-se de hipótese bastante plausível, pois a sobremortalidade masculina brasileira nas últimas décadas tem-se mostrado muito alta, se comparada aos padrões internacionais.

Se essa hipótese de projeção se confirmar, entre 2025 e 2050 haveria um leve aumento da razão de sexo global entre os idosos (de 0,739 para 0,757 ), apesar do declínio da razão entre os mais idosos (de 0,635 para 0,606). 
Distribuição da população idosa, por sexo, segundo a idade, e razão de sexo. Brasil, 2000, 2025 e 2050.

\begin{tabular}{|c|c|c|c|c|}
\hline Período/Grupo etário (anos) & Homens & Mulheres & Ambos os sexos & Razão de sexo \\
\hline \multicolumn{5}{|l|}{2000} \\
\hline Total absoluto (em milhares) & $4.227,5$ & $5.095,8$ & $9.233,3$ & 0,805 \\
\hline Total relativo & 44,6 & 55,4 & 100,0 & - \\
\hline $65-69$ & 16,8 & 19,8 & 36,6 & 0,848 \\
\hline $70-74$ & 12,8 & 15,6 & 28,4 & 0,821 \\
\hline $75-79$ & 7,9 & 10,0 & 17,9 & 0,790 \\
\hline 80 e + & 7,1 & 10,0 & 17,1 & 0,710 \\
\hline \multicolumn{5}{|l|}{2025} \\
\hline Total absoluto (em milhares) & $10.007,5$ & $13.539,7$ & $23.547,2$ & 0,739 \\
\hline Total relativo & 42,5 & 57,5 & 100,0 & - \\
\hline $65-69$ & 16,1 & 20,1 & 36,2 & 0,801 \\
\hline $70-74$ & 11,3 & 14,8 & 26,1 & 0,764 \\
\hline $75-79$ & 7,2 & 10,1 & 17,3 & 0,713 \\
\hline 80 e + & 7,9 & 12,5 & 20,4 & 0,632 \\
\hline \multicolumn{5}{|l|}{2050} \\
\hline Total absoluto (em milhares) & $21.091,0$ & $27.844,0$ & $48.935,0$ & 0,757 \\
\hline Total relativo & 43,1 & 56,9 & 100,0 & - \\
\hline $65-69$ & 13,9 & 15,8 & 29,7 & 0,880 \\
\hline $70-74$ & 10,7 & 13,1 & 23,8 & 0,817 \\
\hline $75-79$ & 7,9 & 10,5 & 18,4 & 0,752 \\
\hline 80 e + & 10,6 & 17,5 & 28,1 & 0,606 \\
\hline
\end{tabular}

Fonte: Organização das Nações Unidas ${ }^{1}$ (dados básicos).

\section{Conclusão}

Considerando-se as relações entre os diversos grupos etários e o ritmo extremamente diferenciado do crescimento da população nas diversas idades, pode-se afirmar que, em termos demográficos, o Brasil está frente a uma janela de oportunidades. Trata-se de um bônus demográfico propiciado pelas mudanças da estrutura etária 7 . O Brasil, à frente da maioria dos países latino-americanos, está num estágio em que, de acordo com Behrman et al. ${ }^{8}$, serão observados alguns dos mais fortes e positivos efeitos da mudança em sua estrutura etária. Em curto e médio prazos, o tamanho menor das gerações de crianças e jovens possibilita, em princípio, um maior retorno dos recursos nelas investidos. É de se esperar um aumento do investimento governamental per capita na educação, mormente nos níveis fundamental e médio, em um contexto demográfico, no qual se destacam duas caracte- rísticas. Por um lado, a diminuição sustentada do peso relativo, quando não do número absoluto, da população jovem e, de outro lado, o aumento ainda pequeno do peso da população idosa. As crianças de hoje constituirão, nas próximas décadas, a força de trabalho que suportará as crescentes razões de dependência de idosos. Deriva disso que a sociedade necessita, vitalmente, investir na atual geração de crianças, particularmente nas áreas de saúde e educação. Não se trata de garantir, apenas, a melhoria da qualidade de vida dessas gerações, mas também o equilíbrio de toda a sociedade. Dependerá das atuais gerações de jovens a garantia, em médio e longo prazos, de uma vida digna às gerações de idosos. Ademais, é nesta fase que a sociedade deve se preparar, mediante reformas institucionais na área da seguridade social (previdência e saúde), para conviver, no futuro próximo, com altas e sustentadas taxas de dependência de idosos. 


\section{Resumo}

A trajetória da população brasileira, na primeira metade deste século, tanto em termos de seu volume, quanto de sua estrutura etária, já está praticamente definida, pois, tanto a transição de mortalidade quanto a da fecundidade já se encontram muito avançadas. Enquanto a população idosa (65 e mais anos de idade) aumentará a taxas altas (entre $2 \%$ e $4 \%$ ao ano), a população jovem tenderá a decrescer. Segundo projeções das Nações Unidas, de 3,1\% da população total, em 1970, a população idosa brasileira deverá passar a aproximadamente 19\%, em 2050. Paralelamente, conviverão dentro das populações jovem e adulta subgrupos etários com crescimento negativo e positivo. A transição etária brasileira gera oportunidades e desafios que, se não aproveitados e enfrentados, no momento devido, levará o país a seriíssimos problemas, nas próximas décadas.

Transição Demográfica; Estrutura Etária; Envelhecimento da População

\section{Colaboradores}

J. A. M. Carvalho foi responsável pela concepção e desenho do artigo. L. L. Rodríguez-Wong colaborou no desenho do artigo, no levantamento bibliográfico, e elaboração do texto. Ambos os autores são responsáveis pela discussão e revisão do conteúdo do artigo.

\section{Referências}

1. United Nations. World population prospects 2004. http://esa.un.org/unpp/p2k0data.asp (acessado em 16/Mai/2006).

2. Instituto Brasileiro de Geografia e Estatística. Projeção da população do Brasil por sexo e idade para o período 1980-2050: revisão 2004. ftp:/ / ftp.ibge.gov. br/Estimativas_Projecoes_Populacao/Revisao_ 2004_Projecoes_1980_2050 (acessado em 16/ Mai/2006).

3. Shryock HS, Siegel JS. The methods and materials of demography. New York: Academic Press; 1976.

4. Centro Latinoamericano y Caribeño de Demografía, Comisión Económica para América Latina y el Caribe. Métodos para proyecciones demográficas. Santiago: Centro Latinoamericano y Caribeño de Demografía, Comisión Económica para América Latina y el Caribe; 1984.

5. Carvalho JAM, Garcia RA. O envelhecimento da população brasileira: um enfoque demográfico. Cad Saúde Pública 2003; 19:725-33.
6. Moreira MM. Envelhecimento da população brasileira [Tese de Doutorado]. Belo Horizonte: Centro de Desenvolvimento e Planejamento Regional, Universidade Federal de Minas Gerias; 1997.

7. Bloom DE, Williamson JG. Demographic transitions and economic miracles in emerging Asia. World Bank Econ Rev 1988; 12:419-56.

8. Behrman JR, Duryea S, Székely M. Aging and economic opportunities: major world regions around the turn of the century. In: Proceedings of the International Union for the Scientific Study of Population, General Conference 24 [CD-ROM]. Paris: International Union for the Scientific Study of Population; 2001.

Recebido em 20/Jul/2006

Versão final reapresentada em 05/Dez/2006 Aprovado em 27/Ago/2007 